\title{
다발신경병 진단에서 신경초음파검사
}

\author{
김정수, 신유용, 김상범
}

강동경희대학교병원 신경과

\section{Nerve Ultrasound in the Assessment of Polyneuropathies}

\author{
Jeong Su Kim, Yu Yong Shin, Sang Beom Kim \\ Department of Neurology, Kyung Hee University Hospital at Gangdong, Seoul, Korea
}

\begin{abstract}
High-resolution ultrasonography (HRUS) is a diagnostic tool that is increasingly used in the work-up of peripheral nerve disease. As many peripheral nerves run a superficial course, they can be studied over a long tract, especially in the arms. This is a big advantage over magnetic resonance imaging (MRI) when multiple nerves have to be studied, as MRI is relatively expensive, time consuming and not readily available everywhere. Furthermore, different aspects of nerve morphology can be studied with HRUS. Nerve cross-sectional area (CSA) can be determined at multiple sites along the nerve. CSA can be measured at entrapment sites (e.g. the carpal tunnel, cubital tunnel, Guyon's canal and the fibular head), but also at non-entrapment sites. Apart from nerve CSA, vascularization, echogenicity, fascicular pattern and endoneurial thickness can be investigated as well. All those modalities can give critical insight in the origin and development of various peripheral neuropathies.
\end{abstract}

Key Words: ultrasonography, polyneuropathy, diagnosis

\section{서 론}

고해상도초음파(high-resolution ultrasonography, HRUS)가 손목굴증후군(carpal tunnel syndrome)과 팔꿈 치척골신경병(ulnar neuropathy at the elbow)과 같은 다 양한 유형의 단일신경병(mononeuropathy)을 진단하고 병 인을 밝히는데 유용하다는 것은 여러 연구들에서 명확하

Received June 14, 2018

Revised December 5, 2018

Accepted February 12, 2019

Corresponding Author: Sang Beom Kim

Department of Neurology, Kyung Hee University Hospital at Gangdong, 892

Dongnam-ro, Gangdong-gu, Seoul 05278, Korea

Tel: 82-2-440-6168, Fax: 82-2-440-7242, E-mail: sbkim@khu.ac.kr
게 정립되었다. ${ }^{1-3}$ 최근 연구들에서는 고해상도초음파가 포 착신경병(entrapment neuropathy) 외에도 다발신경병 (polyneuropathy)을 평가하는데 광범위하게 사용되었다. 본 종설에서는 이에 대한 중요한 성과들을 문답식으로 요약 해 보고자 한다.

\section{본 론}

1) 신경단면적 증가(increased nerve cross-sectional area)가 다발신경병에도 중요한 소견인가?

임상소견과 전기진단검사결과만으로 축삭(axonal)과 탈 수초(demyelinating)다발신경병을 감별하는 것은 쉽지 않 다. 임상양상은 유사할 수 있으며, 전기진단검사결과는 확 정진단을 못 내릴 수도 있어서, 만성염증탈수초다발신경병
Copyright $\odot$ by Korean Association of EMG Electrodiagnostic Medicine
This is an Open Access article distributed under the terms of the Creative Commons Attribution Non-Commercial License (http://creativecommons.org/licenses/by-nc/4.0) which permits unrestricted non-commercial use, distribution, and reproduction in any medium, provided the original work is properly cited. 
(chronic inflammatory demyelinating polyneuropathy, CIDP)과 같은 탈수초신경병을 다른 축삭신경병으로 오진 하는 경우가 종종 있다. ${ }^{4}$ 하지만, CIDP는 치료할 수 있기 때 문에, 치료가 용이하지 않은 축삭다발신경병과 구분하는 것 이 중요하다. 몇몇 연구들에서 고해상도초음파를 이용하 여 비포착부위(non-entrapment site) 신경단면적(crosssectional area, CSA)를 측정하여 탈수초다발신경병을 축삭 다발신경병과 구별할 수 있음을 보고하였다. Zaidman 등은 샤르코-마리-투스병(Charcot-Marie-Tooth disease, CMT) 과 $\mathrm{CIDP}$ 같은 탈수초다발신경병을 정상군 및 축삭다발신경 병 환자군들과 비교했을 때, 신경단면적이 유의하게 증가했 다고 보고하였다. ${ }^{5}$ Scheidl, Grimm, Goedee 등도 탈수초다 발신경병에서 보이는 신경비대(nerve enlargement, 신경단 면적이 정상범위보다 증가하는 경우)가 축삭다발신경병에 서는 보이지 않았다고 보고하였다. ${ }^{6-9}$ 이러한 소견들은 고해 상도초음파가 치료가능한 탈수초다발신경병 환자들을 진단 하는 유용한 수단임을 명백하게 보여준다.

축삭다발신경병과 탈수초다발신경병을 감별하는 것 외 에도, 탈수초다발신경병의 다양한 아형들을 구분하는 것 도 중요한데, 그 이유는 탈수초다발신경병이 전부 치료가 능한 것은 아니기 때문이다. CIDP와 같은 후천염증탈수 초다발신경병(acquired inflammatory demyelinating polyneuropathy)은 코르티코스테로이드(corticosteroid), 면역글로불린정맥주사(intravenous immunoglobulin, IVIg), 혈장분리교환술(plasmapheresis) 등으로 치료되 지만, CMT1과 같은 유전탈수초다발신경병(hereditary demyelinating polyneuropathy)에서는 아직 효과적인 치 료방법이 나오지 않았다. 여러 연구들에서 고해상도초음파 가 이 질환군들을 감별하는데 도움이 된다고 하였다. CMT1 환자들은 흔히 신경이 크게 비대해지는데 반해, CIDP 환 자들에서는 중등도로, 길랭-바레증후군(Guillain-Barre syndrome, GBS) 환자들에서는 경도로 신경단면적이 증가 됨이 보고되었다. ${ }^{5,10}$ 이 연구는 유전성과 후천성 탈수초다발 신경병의 초음파 소견의 차이를 분석한 선구자적인 연구이 지만 후천탈수초다발신경병 환자가 적은 것이 한계이다. 따 라서 후천성 탈수초다발신경병의 초음파 연구결과들을 분 석할 때 비교를 위해 참고할 만하다. Sugimoto 등도 신경단 면적이 $\mathrm{CIDP}$ 보다 $\mathrm{CMT}$ 에서 유의하게 증가된다고 보고하였 다. ${ }^{11}$ 고해상도초음파는 유전다발신경병군 내에서 여러 유형 들을 감별하는데 도움이 된다. $\mathrm{CMT} 1 \mathrm{~A}$ 는 신경비대가 가장 현저하지만, CMT1B와 CMTX는 신경에서 경도의 비대가
보인다. 축삭CMT인 CMT2에서는 아직 유의한 신경비대가 보고된 바 없다. ${ }^{10,12,13}$ 그러므로 고해상도초음파로 신경비대 의 양상을 보고 탈수초다발신경병의 아형을 결정하여, 향후 유전신경병이 의심되는 경우에 유전자검사의 방향까지 결 정할 수 있을 것으로 기대된다.

또 다른 중요한 점은 임상에서 흔히 하는 고민인데, 근위 축측삭경화증(amyotrophic lateral sclerosis, ALS)과 같은 운동신경세포질환(motor neuron disease, MND)과 다초 점운동신경병(multifocal motor neuropathy, $\mathrm{MMN}$ )의 감 별이 쉽지 않다는 점이다. 이들 질환은 임상적으로 매우 유 사하지만, 예후와 치료방법이 전혀 다르다. 고해상도초음 파는 이 두 질환을 감별하는데 중요한 단서를 제공한다. 즉, $\mathrm{MMN}$ 에서는 신경비대가 관찰되었으나, MND에서는 보이 지 않았다. ${ }^{6,14,15} \mathrm{Grimm}$ 등은 고해상도초음파가 $87.5 \%$ 의 민감도와 94.1\%의 특이도로 MMN과 $\mathrm{ALS}$ 를 감별할 수 있 다고 보고하였고, ${ }^{14}$ 최근 Goedee 등은 첫 치료를 받게 된 (treatment-naïve) CIDP 환자군을 95\%의 민감도(95\% 신 뢰구간: 78 99\%)와 100\%의 신뢰도로 $\mathrm{MMN}$ 과 감별할 수 있다고 발표하였다. ${ }^{6}$

위에서 언급된 질병 외에도, 다초점염증탈수초신경병 (multifocal inflammatory demyelinating neuropathy, Lewis-Sumner증후군, MADSAM), 압박마비취약유전신 경병(hereditary neuropathy with liability to pressure palsy, HNPP), 당뇨다발신경병, 항MAG다발신경병, 나 병신경병, 혈관염다발신경병, $\mathrm{POEMS}$ 증후군, 신생물딸 림신경병(paraneoplastic neuropathy), 신경섬유종증 (neurofibromatosis)과 같은 다양한 질환에서 신경비대가 보고되어 왔다(Table 1). ${ }^{16} \mathrm{GBS}$ 에서도 신경비대가 보였는 데, ${ }^{17}$ 때때로 질병 초기에도 관찰되었다. ${ }^{18}$ 신경전도검사는 보통 질병이 진행된 다음에 이상이 관찰되므로, 고해상도초 음파는 진단 초기에 추가적인 정보를 제공할 수 있다. 그러 나, GBS에서 보이는 신경비대는 보통 현저하지 않으면서 다 발성으로 발생하고, 발생시기가 환자마다 다를 수 있어서, $\mathrm{GBS}$ 를 평가하는 데에는 한계가 있다.

\section{2) 초음파소견의 정량화(quantifying abnormalities)가 진단법을 개선하는가?}

신경단면적(nerve CSA)뿐만 아니라 신경단면적을 이용한 여러 점수체계와 프로토콜들이 다발신경병의 유형을 구분 하기 위하여 개발되었다. Padua 등은 다발신경병 분류를 개 선하기 위하여 신경내 변이도(intranerve CSA variability, 
Table 1. Ultrasound Findings in Polyneuropathies and Motor Neuron Diseases

\begin{tabular}{|c|c|}
\hline Diseases & Ultrasound Findings \\
\hline $\begin{array}{l}\text { Charcot-Marie } \\
\text { Tooth Disease }\end{array}$ & $\begin{array}{l}\text { Demyelinating forms have CSAs } 2.0 \sim 4.0 \times \\
\text { that of controls in the median and ulnar } \\
\text { nerves } \\
\text { Axonal forms have CSA } 1.5 \sim 2.0 \times \text { that of } \\
\text { controls in the median and ulnar nerves } \\
\text { The sural nerve is only enlarged in children }\end{array}$ \\
\hline $\begin{array}{l}\text { Multifocal Motor } \\
\text { Neuropathy } \\
\text { (MMN) }\end{array}$ & $\begin{array}{l}\text { Patchy increased CSA with inter- and intra- } \\
\text { nerve variability; includes the brachial } \\
\text { plexus } \\
\text { Focal nerve enlargements can differentiate } \\
\text { MMN from ALS } \\
\text { Nerve enlargement does not correlate well } \\
\text { with conduction block }\end{array}$ \\
\hline $\begin{array}{l}\text { Guillain-Barre } \\
\text { Syndrome }\end{array}$ & $\begin{array}{l}\text { Nerves may be enlarged before changes are } \\
\text { detected by electrodiagnosis } \\
\text { Nerve enlargement is reversible with } \\
\text { recovery }\end{array}$ \\
\hline $\begin{array}{l}\text { Chronic } \\
\text { Inflammatory } \\
\text { Demyelinating } \\
\text { Polyneuropathy }\end{array}$ & $\begin{array}{l}\text { Patchy nerve enlargement } \\
\text { The site of focal enlargement does not always } \\
\text { correlate with slowed conduction velocity }\end{array}$ \\
\hline $\begin{array}{l}\text { Diabetic } \\
\text { Polyneuropathy }\end{array}$ & $\begin{array}{l}\text { Nerve changes are subtle and not particularly } \\
\text { helpful for diagnosis } \\
\text { Intrinsic foot muscle atrophy can be readily } \\
\text { detected }\end{array}$ \\
\hline $\begin{array}{l}\text { Vasculitic } \\
\text { Polyneuropathy } \\
\text { Leprosy }\end{array}$ & $\begin{array}{l}\text { Minor increase in nerve CSA } \\
\text { Can guide selection of nerve biopsy site } \\
\text { Ulnar nerve CSA enlargement } \\
\text { Increased epineurial thickness } \\
\text { Increased vascularity }\end{array}$ \\
\hline $\begin{array}{l}\text { Amyotrophic } \\
\text { Lateral Sclerosis } \\
\text { (ALS) }\end{array}$ & $\begin{array}{l}\text { Normal to slightly decreased nerve CSA } \\
\text { Muscle atrophy and increased echogenicity } \\
\text { Ultrasound is more sensitive for the detection } \\
\text { of fasciculations than visual inspection or } \\
\text { EMG } \\
\text { Diaphragm thinning and increased } \\
\text { echogenicity } \\
\text { May be a responsive biomarker of disease } \\
\text { progression }\end{array}$ \\
\hline
\end{tabular}

동일 신경의 주행 경로 중 측정된 최대 단면적과 최소 단면 적의 비)와 신경간 변이도(internerve CSA variability, 동 일 환자의 최대 신경내변이도와 최소 신경내변이도의 비) 를 제안하였다. ${ }^{19}$ Kerasnoudis 등은 염증신경병에서 급성염 증탈수초다발신경병(acute inflammatory demyelinating polyneuropathy, AIDP), MMN, MADSAM을 CIDP와 구별 하기 위하여 Bochum초음파점수체계(Bochum ultrasound Score, BUS)를 고안하였고, ${ }^{20}$ Guyon굴과 위팔의 척골신 경, 위팔 나선고랑(spiral groove)의 요골신경, 장딴지근 (gastrocnemius)에서 장딴지신경(sural nerve)의 신경단면
적을 측정하여 $\mathrm{CIDP}$ 가능성을 예측하였다. ${ }^{21} \mathrm{Grimm}$ 등도 급성과 아급성다발신경병을 감별하기 위하여 초음파유형 합산점수체계(ultrasound pattern sum score, UPSS)를 개 발하였는데, ${ }^{9}$ 상하지의 운동신경(UPS-A), 경추신경뿌리와 미주신경(UPS-B), 장딴지신경(UPS-C)의 신경단면적을 합 산하여 총점을 내고, 감별진단을 제안한다. 수정(modified) $\mathrm{UPSS}$ 는 유전다발신경병의 아형을 구별하는 데에도 사용된 다. ${ }^{13}$ Goedee 등은 최근 상완신경총(위, 중간, 아래 줄기), 위팔과 아래팔의 정중신경을 평가하는 단축프로토콜을 제 안하여, 후천탈수초다발신경병과 축삭신경병을 구분하였고, $\mathrm{MMN}$ 과 MND를 감별하였다. ${ }^{6}$

다발신경병의 진단법을 개선하기 위하여 이러한 여러가 지 초음파 점수체계와 프로토콜들이 개발되었으나, 보편적 으로 적용되기 위해서는 검증이 필요하다. Grimm 등의 연 구에서 BUS와 UPSS의 사용이 다발신경병의 감별진단에 유 용함을 입증하였지만, 이 연구에 포함된 환자들 중 상당수가 이미 확정진단을 받고 장기치료 중인 환자들이었다. ${ }^{22}$ 따라 서 표준화 점수체계나 프로토콜이 실제 임상현장에서 유용 한지를 확인하기 위하여 치료를 처음으로 시작한 환자들을 대상으로 한 대규모의 전향연구가 시행될 필요가 있다.

\section{3) 신경다발크기(fascicle size), 신경외막(epineurium)} 크기, 에코강도(echo-intensity), 혈관분포도 (vascularity) 등도 중요한 신경형태의 특징인가?

신경단면적은 가장 용이하게 측정되며 가장 많이 연구 된 다발신경병의 특징으로, 신경의 다른 특징들도 연구되고 있다. 신경다발크기의 증가가 CMT와 CIDP에서 보고되었 고 ${ }^{23,24}$ 나병신경병에서 신경의 혈관분포도 증가와 두꺼워진 신경외막이 관찰되었다. ${ }^{25,26}$ 신경에코발생도의 이상은 단일 신경병에서는 확인되었으나, 다발신경병에서 아직 충분히 평가되지는 못하였다. ${ }^{17}$ Padua 등은 CIDP에서 초음파검사 결과 신경단면적, 신경다발크기 그리고 에코발생도에 따라 $\mathrm{CIDP}$ 의 이환기간과 예후가 달랐다고 보고하였다. ${ }^{27}$ 예를 들 어, 신경단면적이 정상인데 신경의 에코강도가 감소한 환자 는 신경단면적이 약간 증가했지만 에코강도가 정상인 환자 보다 예후가 좋지 않았던 것으로 나타났다. ${ }^{22,27}$

이와 같이 신경단면적이 아닌 별개의 신경형태의 이상소 견들이 보고되고 있으며, 다발신경병의 진단을 위한 역할과 예후에 미치는 영향을 알기 위해 더 많은 연구가 필요하다. 


\section{4) 신경비대의 분포 유형이 신경단면적의 증가와는 다른 임상 정보를 제공하는가?}

신경비대는 다양한 유형의 다발신경병에서 관찰되었다. 형태이상의 분포에 대한 정보가 축적됨에 따라, 여러 유형 의 다발신경병에서 서로 다른 신경비대의 양상들이 알려지 기 시작했다. CMT에서는 광범위한 신경비대가 보였는데, CMT1A에서 뚜렷하고, CMT1B와 CMTX에서는 정도가 덜 했다. ${ }^{10,11,13,28} \mathrm{CIDP}$ 에서도 편만한 신경비대가 관찰되었지만, 신경 근위부의 대칭적인 비대가 더 흔히 보였다. ${ }^{5-7,10,11,29,30}$ $\mathrm{MMN}$ 에서는 근위부에서 신경비대가 보였으나, 비대칭적이 고 국소적인 이상이 더 흔했다. ${ }^{6,10,31,32}$ 비포착부위에서 광범 위한 신경비대를 보인 CMT와는 달리 HNPP에서는 포착부 위에서 두드러지게 신경비대가 관찰되었으며, ${ }^{14,28}$ 비포착부 위 신경비대는 산발적으로 보고되었다. ${ }^{33}$ 축삭다발신경병 (당뇨다발신경병, 화학요법유발다발신경병)은 포착부위의 경도 신경비대 이외에 신경비대는 관찰되지 않았다. ${ }^{5,8,34}$ 예 외적으로 혈관염신경병에서 비포착부위의 신경비대가 경도 로 보였지만, 상완신경총은 정상이었다. ${ }^{35,36}$ 나병신경병에서 는 포착부위에서 신경비대가 보이지 않았지만, 근위부 특히 팔꿈치굴 근위부에서는 신경비대가 관찰되었다. ${ }^{25,35}$ 다양한 유형의 다발신경병에서 초음파이상소견의 분포가 서로 달 랐기 때문에, 신경비대의 양상은 특정 다발신경병 진단을 위 한 단서를 제공할 수 있으므로, 추가적인 연구가 필요하다.

\section{5) 고해상도초음파는 진단도구 외에도 적용될 수 있는가?}

고해상도초음파는 진단적 적용 외에도 다발신경병의 장 기적인 예후와 치료반응을 예측하는데 도움이 될 수 있다. Zaidman 등은 후향연구에서 신경초음파 추적검사 중 신경 단면적이 감소된 CIDP 환자들에서 신경단면적이 증가되 거나 유지된 환자들보다 더 치료반응이 좋았음을 보고하였 다. ${ }^{38}$ Kerasnoudis 등은 소규모 전향연구에서 신경내 변이 도가 감소할수록 CIDP에서 예후가 양호했음을 보고하였 다. ${ }^{39}$ Chaduvula 등은 2년간 57명의 나병신경병 환자들의 질병활성도를 연구하였는데, 나병반응(leprosy reaction, 나 병 경과 중 발생하는 면역매개 급성 또는 아급성 염증)이 있 는 환자들에서 처음 방문시보다 신경비대가 정상군보다 유 의하게 증가했고, 나병반응이 없는 환자들에서는 경도로 신 경비대가 발생했다고 보고하였다. ${ }^{40}$ 또한 나병반응이 없던 환자들은 추적기간 동안 신경크기에 큰 변화가 없는 반면, 나병반응이 있던 환자들에서는 치료가 효과적인 경우 혈관 분포도와 신경크기가 큰 폭으로 감소하였으며, 이러한 치료
에 따른 혈관분포도의 감소는 Lugão 등의 연구에서도 보고 되었다. ${ }^{41}$

이들 연구 결과들은 초음파의 예후 추정 역할에 고무적으 로, 고해상도초음파의 질병 예후 예측에 대한 연구는 치료성 과에 대한 연구와 더불어 더 많은 환자들을 대상으로 전향적 으로 이루어질 필요가 있다.

고해상도초음파는 말초신경병의 선별검사로도 유용하게 쓰일 수 있는데, 최근 연구에서 신경섬유종증 환자에서 말초 신경계 침범이 흔하다고 보고되었다. ${ }^{42}$ 한 연구에서는 17 명 의 1 형 신경섬유종증 환자 중 $41.2 \%$ 에서 다발얼기신경섬유 종(multiple plexiform neurofibroma)을 보고하였고, ${ }^{43}$ 이 다발얼기섬유종은 향후 사망률을 증가시키는 악성변형을 일으키는 위험인자가 된다. 따라서, 신경섬유종환자들에서 악성화 위험인자 평가를 위한 정기적인 초음파 추적검사가 필요하며, 신경수초종양의 치료반응을 평가하는데 쓰일 수 도 있다.

\section{결 론}

말초신경병에서 고해상도초음파의 진단적 적용에 대한 연 구들은 최근 광범위하게 수행되어 긍정적인 결과들을 보여 주고 있다. 축삭다발신경병과 탈수초다발신경병을 감별할 수 있을 뿐만 아니라 탈수초다발신경병의 여러 유형들을 분 류할 수 있다. 신경단면적 측정은 말초신경병을 구분하는데 가장 유용하지만, 초음파 이상소견의 분포양상도 특정진단 을 내리는데 중요한 단서를 제공할 수 있다. 또한, 초음파 점 수체계와 프로토콜들이 개발되어 고해상도초음파가 말초신 경병의 여러 유형들을 감별하는데 기여하고 있다.

고해상도초음파는 진단적 적용과는 별도로 말초신경병의 예후에 대한 정보도 제공할 수 있다. 특정 말초신경병에서 신경단면적과 혈관분포도의 변화가 예후 및 치료반응과 상 관관계가 있는 것으로 알려져 있다. 이러한 연구결과들은 초 음파의 유망한 활용을 시사하지만, 더 많은 연구들이 말초신 경병을 평가할 때 초음파의 역할을 정립하기 위해 필요하다. 다양한 연구들에서 사용된 초음파연구 프로토콜들은 서로 상당히 달랐고, 일부 연구들에서만 신경단면적이 아닌 에코 발생도, 혈관분포도 등의 신경 형태의 특징들을 연구하였다. 또한, 대부분의 연구들이 표본수가 비교적 작고 후향연구였 으며, 단일기관에서 단일장비로 단독 혹은 적은 수의 연구자 들이 수행했다. 따라서 다기관이 참여하여 초음파로 다발신 경병의 진단과 예후를 연구하고 신경초음파의 가치를 평가 
하는 대규모의 전향연구들이 필요하다. 신경초음파를 할 때 검사자간 변이도의 영향도 정립되어야 하는데 여러 연구들 에서 확인된 신경초음파의 진단 결정치(cut-off value)를 임 상진료에 적용할 수 있는지를 결정하기 위해서이다.

\section{References}

1. Beekman R, Visser LH: Sonography in the diagnosis of carpal tunnel syndrome: a critical review of the literature. Muscle Nerve 2003: 27: 26-33

2. Beekman R, Visser LH: High-resolution sonography of the peripheral nervous system-a review of the literature. Eur J Neurol 2004: 11: 305-314

3. Beekman R, Visser LH, Verhagen WI: Ultrasonography in ulnar neuropathy at the elbow: a critical review. Muscle Nerve 2011: 43: 627-635

4. Allen JA, Lewis RA: CIDP diagnostic pitfalls and perception of treatment benefit. Neurology 2015: 85: 498-504

5. Zaidman CM, Al-Lozi M, Pestronk A: Peripheral nerve size in normals and patients with polyneuropathy: an ultrasound study. Muscle Nerve 2009: 40: 960-966

6. Goedee HS, van der Pol WL, van Asseldonk JH, Franssen H, Notermans NC, Vrancken AJ, et al: Diagnostic value of sonography in treatment-naïve chronic inflammatory neuropathies. Neurology 2017: 88: 143-151

7. Scheidl E, Böhm J, Simó M, Bereznai B, Bereczki D, Arányi Z: Different patterns of nerve enlargement in polyneuropathy subtypes as detected by ultrasonography. Ultrasound Med Biol 2014: 40: 1138-1145

8. Grimm A, Heiling B, Schumacher U, Witte OW, Axer H: Ultrasound differentiation of axonal and demyelinating neuropathies. Muscle Nerve 2014: 50: 976-983

9. Grimm A, Décard BF, Axer H, Fuhr P: The ultrasound pattern sum score-UPSS. A new method to differentiate acute and subacute neuropathies using ultrasound of the peripheral nerves. Clin Neurophysiol 2015: 126: 2216-2225

10. Zaidman CM, Harms MB, Pestronk A: Ultrasound of inherited vs. acquired demyelinating polyneuropathies. J Neurol 2013: 260: 3115-3121

11. Sugimoto T, Ochi K, Hosomi N, Takahashi T, Ueno H, Nakamura $\mathrm{T}$, et al: Ultrasonographic nerve enlargement of the median and ulnar nerves and the cervical nerve roots in patients with demyelinating Charcot-Marie-Tooth disease: Distinction from patients with chronic inflammatory demyelinating polyneuropathy. J Neurol 2013: 260: 2580-2587

12. Schreiber S, Oldag A, Kornblum C, Kollewe K, Kropf S,
Schoenfeld A, et al: Sonography of the median nerve in CMT1A, CMT2A, CMTX, and HNPP. Muscle Nerve 2013: 47: 385-395

13. Grimm A, Rasenack M, Athanasopoulou IM, Dammeier NM, Lipski C, Wolking S, et al: The modified ultrasound pattern sum score mUPSS as additional diagnostic tool for genetically distinct hereditary neuropathies. J Neurol 2016: 263 : 221-230

14. Grimm A, Décard BF, Athanasopoulou I, Schweikert K, Sinnreich M, Axer H: Nerve ultrasound for differentiation between amyotrophic lateral sclerosis and multifocal motor neuropathy. J Neurol 2015: 262: 870-880

15. Loewenbruck KF, Liesenberg J, Dittrich M, Schäfer J, Patzner B, Trausch B, et al: Nerve ultrasound in the differentiation of multifocal motor neuropathy (MMN) and amyotrophic lateral sclerosis with predominant lower motor neuron disease (ALS/LMND). J Neurol 2016: 263: 35-44

16. Shen J, Cartwright MS: Neuromuscular Ultrasound in the Assessment of Polyneuropathies and Motor Neuron Disease. J Clin Neurophysiol 2016: 33: 86-93

17. Goedee HS, Brekelmans GJ, van Asseldonk JT, Beekman R, Mess WH, Visser LH: High resolution sonography in the evaluation of the peripheral nervous system in polyneuropathy - a review of the literature. Eur J Neurol 2013: 20: 13421351

18. Grimm A, Decard BF, Axer H: Ultrasonography of the peripheral nervous system in the early stage of Guillain-Barre syndrome. J Peripher Nerv Syst 2014: 19: 234-241

19. Padua L, Martinoli C, Pazzaglia C, Lucchetta M, Granata G Erra C, et al: Intra- and internerve cross-sectional area variability: new ultrasound measures. Muscle Nerve 2012: 45: 730-733

20. Kerasnoudis A, Pitarokoili K, Behrendt V, Gold R, Yoon MS: Nerve ultrasound score in distinguishing chronic from acute inflammatory demyelinating polyneuropathy. Clin Neurophysiol 2014: 125: 635-641

21. Kerasnoudis A, Pitarokoili K, Gold R, Yoon MS: Bochum ultrasound score allows distinction of chronic inflammatory from multifocal acquired demyelinating polyneuropathies. J Neurol Sci 2015: 348: 211-215

22. Grimm A, Rattay TW, Winter N, Axer H: Peripheral nerve ultrasound scoring systems: benchmarking and comparative analysis. J Neurol 2017: 264: 243-253

23. Martinoli C, Schenone A, Bianchi S, Mandich P, Caponetto C, Abbruzzese M, et al: Sonography of the median nerve in Charcot-Marie-Tooth disease. Am J Roentgenol 2002: 178: 1553-1556 
24. Granata G, Pazzaglia C, Caliandro P, Martinoli C, Padua L: Letter to the editor referring to "Peripheral nerve hypertrophy in chronic inflammatory demyelinating polyradiculoneuropathy detected by ultrasonography". Intern Med 2009: 48: 2049

25. Jain S, Visser LH, Praveen TL, Rao PN, Surekha T, Ellanti R, et al: High-resolution sonography: a new technique to detect nerve damage in leprosy. PLoS Negl Trop Dis 2009: 3: e498

26. Visser LH, Jain S, Lokesh B, Suneetha S, Subbanna J: Morphological changes of the epineurium in leprosy: a new finding detected by high-resolution sonography. Muscle Nerve 2012: 46: 38-41

27. Padua L, Granata G, Sabatelli M, Inghilleri M, Lucchetta M, Luigetti M, et al: Heterogeneity of root and nerve ultrasound pattern in CIDP patients. Clin Neurophysiol 2014: 125: 160165

28. Goedee SH, Brekelmans GJ, van den Berg LH, Visser LH: Distinctive patterns of sonographic nerve enlargement in Charcot-Marie-Tooth type 1A and hereditary neuropathy with pressure palsies. Clin Neurophysiol 2015: 126: 14131420

29. Jang JH, Cho CS, Yang KS, Seok HY, Kim BJ: Pattern analysis of nerve enlargement using ultrasonography in chronic inflammatory demyelinating polyneuropathy. Clin Neurophysiol 2014: 125: 1893-1899

30. Di Pasquale A, Morino S, Loreti S, Bucci E, Vanacore N, Antonini G: Peripheral nerve ultrasound changes in CIDP and correlations with nerve conduction velocity. Neurology 2015: 84: 803-809

31. Kerasnoudis A: Correlation of sonographic and electrophysiological findings in a patient with multifocal motor neuropathy. J Neuroimaging 2014: 24: 305-307

32. Beekman R, van den Berg LH, Franssen H, Visser LH, van Asseldonk JT, Wokke JH: Ultrasonography shows extensive nerve enlargements in multifocal motor neuropathy. Neurology 2005: 65: 305-307

33. Beekman R, Visser LH: Sonographic detection of diffuse peripheral nerve enlargement in hereditary neuropathy with liability to pressure palsies. J Clin Ultrasound 2002: 30: 433436
34. Briani C, Campagnolo M, Lucchetta M, Cacciavillani M, Dalla Torre C, Granata G, et al: Ultrasound assessment of oxaliplatin-induced neuropathy and correlations with neurophysiologic findings. Eur J Neurol 2013: 20: 188-192

35. Goedee HS, van der Pol WL, van Asseldonk JTH, Vrancken AFJE, Notermans NC, Visser LH, et al: Nerve sonography to detect peripheral nerve involvement in vasculitis syndromes. Neurology: Clinical Practice 2016: 6: 1-11

36. Grimm A, Décard BF, Bischof A, Axer H: Ultrasound of the peripheral nerves in systemic vasculitic neuropathies. Journal of the neurological sciences 2014: 347: 44-49

37. Martinoli C, Derchi LE, Bertolotto M, Gandolfo N, Bianchi $\mathrm{S}$, Fiallo P, et al: US and MR imaging of peripheral nerves in leprosy. Skeletal Radiol 2000: 29: 142-150

38. Zaidman CM, Pestronk A: Nerve size in chronic inflammatory demyelinating neuropathy varies with disease activity and therapy response over time: a retrospective ultrasound study Muscle Nerve 2014: 50: 733-738

39. Kerasnoudis A, Pitarokoili K, Gold R, Yoon MS: Nerve ultrasound and electrophysiology for therapy monitoring in chronic inflammatory demyelinating polyneuropathy. J Neuroimaging 2015: 25: 931-939

40. Chaduvula MV, Visser LH, Suneetha S, Suneetha L, Devaraju B, Ellanti R, et al: High-resolution sonography as an additional diagnostic and prognostic tool to monitor disease activity in leprosy: a two-year prospective study. Ultraschall Med 2018: 39: 80-89

41. Lugão HB, Frade MA, Marques W Jr, Foss NT, NogueiraBarbosa MH: Ultrasonography of leprosy neuropathy: a longitudinal prospective study. PLoS Negl Trop Dis 2016: 10: e0005111

42. Winter N, Rattay TW, Axer H, Schäffer E, Décard BF, Gugel I, et al: Ultrasound assessment of peripheral nerve pathology in neurofibromatosis type 1 and 2. Clin Neurophysiol 2017: 128: 702-706

43. Telleman JA, Stellingwerff MD, Brekelmans GJ, Visser LH: Nerve ultrasound: A useful screening tool for peripheral nerve sheath tumors in NF1? Neurology 2017: 88: 16151622 